\title{
Ecological status assessment of European lakes: a comparison of metrics for phytoplankton, macrophytes, benthic invertebrates and fish
}

\author{
Anne Lyche-Solheim • Christian K. Feld • Sebastian Birk • Geoff Phillips • \\ Laurence Carvalho • Giuseppe Morabito • Ute Mischke • Nigel Willby • \\ Martin Søndergaard • Seppo Hellsten • Agnieszka Kolada • Marit Mjelde • \\ Jürgen Böhmer • Oliver Miler • Martin T. Pusch • Christine Argillier • \\ Erik Jeppesen - Torben L. Lauridsen • Sandra Poikane
}

Received: 1 November 2012/ Accepted: 15 December 2012/Published online: 1 February 2013

(C) The Author(s) 2013. This article is published with open access at Springerlink.com

\begin{abstract}
Data on phytoplankton, macrophytes, benthic invertebrates and fish from more than 2000 lakes in 22 European countries were used to develop and test metrics for assessing the ecological status of European lakes as required by the Water Framework Directive. The strongest and most sensitive of the 11 metrics responding to eutrophication pressure were phytoplankton chlorophyll a, a taxonomic composition trophic index and a functional traits index, the
\end{abstract}

Guest editors: C. K. Feld, A. Borja, L. Carvalho \& D. Hering / Water bodies in Europe: integrative systems to assess ecological status and recovery

A. Lyche-Solheim $(\bowtie) \cdot$ M. Mjelde

Norwegian Institute for Water Research (NIVA),

Gaustadalléen 21, 0349 Oslo, Norway

e-mail: als@niva.no

C. K. Feld · S. Birk

Faculty of Biology, University of Duisburg-Essen (UDE),

Universitaetsstrasse 2, 45141 Essen, Germany

G. Phillips

Environment Agency, Kings Meadow Road,

Reading Berkshire RG1 8DQ, UK

L. Carvalho

Centre for Ecology \& Hydrology, Bush Estate, Penicuik, Midlothian EH26 0QB, UK

G. Morabito

CNR Institute for Ecosystems Study, Largo V. Tonolli 50, 28922 Verbania Pallanza, Italy macrophyte intercalibration taxonomic composition metric and a Nordic lake fish index. Intermediate response was found for a cyanobacterial bloom intensity index (Cyano), the Ellenberg macrophyte index and a multimetric index for benthic invertebrates. The latter also responded to hydromorphological pressure. The metrics provide information on primary and secondary impacts of eutrophication in the pelagic and the littoral zone of lakes. Several of these metrics were used as common metrics in the intercalibration of national assessment systems or have been incorporated directly into the national systems. New biological metrics have been developed

\author{
U. Mischke · O. Miler · M. T. Pusch \\ Dept. of Ecosystem Research, Müggelseedamm, Leibniz- \\ Institute of Freshwater Ecology and Inland Fisheries \\ (IGB) 310, 12587 Berlin, Germany \\ N. Willby \\ University of Stirling, Biological \& Environmental \\ Science, University of Stirling, Stirling FK9 4LA, UK \\ M. Søndergaard · E. Jeppesen · T. L. Lauridsen \\ Department of Bioscience, Aarhus University, \\ Vejlsøvej 25, P.O. Box 314, 8600 Silkeborg, Denmark \\ S. Hellsten \\ Finnish Environment Institute (SYKE), \\ Freshwater Centre, P.O. Box 413, 90014 Oulu, Finland
}

A. Kolada

Insitute for Environmental Protection (IEP) - National Research Institute, Krucza 5/11 d, 00-548 Warsaw, Poland 
to assess hydromorphological pressures, based on aquatic macrophyte responses to water level fluctuations, and on macroinvertebrate responses to morphological modifications of lake shorelines. These metrics thus enable the quantification of biological impacts of hydromorphological pressures in lakes.

Keywords Lakes - Europe - Biological metrics · Eutrophication · Hydromorphology · Uncertainty · Water Framework Directive

\section{Introduction}

The value of lakes cannot simply be measured in terms of their water volume and chemical quality. We also value lakes if they have clear water free of algal blooms suitable for water supply and recreation, rich biodiversity worthy of conservation and attractive to tourism, and can act as healthy ecosystems for water purification and climate regulation (MEA, 2005). The most effective methods to determine the health and integrity of our lakes are the plants and animals living there. Biological monitoring provides a direct picture of a lake's status and is much easier understood by the public than chemical data alone. Moreover, in the scientific literature it is widely recognised that biological monitoring schemes have many advantages compared to chemical monitoring schemes (Mason, 1981; Karr \& Chu, 1999). Biological metrics respond to intermittent pollution, integrating the effect of stressors over longer timescales (weeks to years), compared to chemical monitoring which provides a single 'snap-shot' of the quality at the time of sampling. These aspects of lake biology are the underlying reasons why phytoplankton, macrophytes,

\section{J. Böhmer}

Bioforum GmbH, Sudetenstr. 34, 73230 Kirchheim/Teck, Germany

C. Argillier

IRSTEA, UR HYAX Hydrobiologie,

13182 Aix-en-Provence, France

\section{S. Poikane}

European Commission, Joint Research Centre, Institute for Environment and Sustainability, Via E. Fermi 2749, 21027 Ispra (VA), Italy benthic invertebrates and fish are now required for the assessment of the ecological status of lakes in Europe according to the EC Water Framework Directive (WFD): (EC, 2000). Annex V of the WFD outlines the technical requirements for using various characteristics of these four biological quality elements (BQEs) in the assessment: for phytoplankton these are biomass, taxonomic composition and bloom metrics; for macrophytes taxonomic composition and abundance; for benthic invertebrates taxonomic composition, abundance and diversity and for fish taxonomic composition, abundance and age structure. Although some national metrics expressing the responses of several of these characteristics to human pressures were developed and used in lake monitoring programmes prior to the WFD, the Directive has stimulated the development and improvement of a large array of different national methods (Lyche Solheim et al., 2008; Solimini et al., 2008; Poikane, 2009; Birk et al., 2012; Brucet et al., 2013).

The diverse array of national methods has posed great challenges in assessing the comparability of national methods, a process known as intercalibration' required by the WFD (WFD CIS, 2009). To facilitate the WFD intercalibration process, there was an urgent need to develop pressure-specific metrics for all BQEs to be used as robust indicators in national methods or as 'common metrics', which allow the comparison of national methods between countries.

Most national metrics address eutrophication, which is still the most widespread pressure in European lakes (EEA-ETC, 2012). However, hydromorphological pressure (e.g. altered water level regime, shoreline modification) is an increasingly important pressure in many lakes in Europe (EEA-ETC, 2012), and biological indicators addressing impacts of hydromorphological alteration need to be included in monitoring programmes.

There is a need to know which metrics are least affected by natural and methodological variation, and thus best reflect the most widespread pressures affecting our lakes, and, therefore, exhibit minimal uncertainties when using them. Variation in metric values, which may obscure the effects of environmental stress that the evaluator wants to assess, is due to (i) sampling variation and inconsistent sampling method; (ii) sample processing and taxonomic identification bias and (iii) natural temporal and spatial variation. Quantification and subsequent reduction of 
the various uncertainty components is important to optimise sampling design and reduce uncertainty in the classification of the ecological status of lakes.

The objective of this paper is to present an overview of all the metrics and multimetric indices developed for lakes in the WISER EU FP 7 project (www. wiser.eu) (Hering et al., 2013) for phytoplankton, macrophytes, benthic invertebrates and fish, and assess their strengths and sensitivities to the main pressures, as well as their main sources of variability. Many of the metrics have been developed to reflect the impact of nutrient pressures (eutrophication). In addition, metrics have been developed to address the impacts of hydromorphological pressures on macrophytes and benthic invertebrates.

Details on the development and uncertainty of each of these metrics are given in the other papers in this special issue (e.g. Carvalho et al., 2012; Phillips et al., 2012; Dudley et al., 2012; Mjelde et al., 2012; Argillier et al., 2012; Clarke, 2012) or are published elsewhere (e.g. Kolada et al., 2011; Böhmer et al., 2011; Sandin \& Solimini, 2012; Pilotto et al., 2011; Miler et al., 2012; Emmrich et al., 2011, 2012a, b).

\section{Data and methods for metrics tested for eutrophication response}

Data

Data from more than 2000 lakes from 22 European countries were used to develop the eutrophicationrelated metrics (Table 1). The data are stored in a central database and are further described by Moe et al. (2012). The above listed papers focus on the individual BQEs, including the datasets underlying the regressions presented in this synthesis. Within-lake variability in metrics has been assessed from new WISER data collected from 26 to 51 lakes in 2009-2010 (Table 2).

\section{Lake types and regions}

Most of the metrics responding to eutrophication are identified from data for many lake types within different European regions used in the intercalibration of national assessment systems, referred to as 'Geographic Intercalibration Regions (GIGs)' (Poikane, 2009). Most of the data were from the Northern and
Table 1 WISER data available for developing metrics responding to eutrophication

\begin{tabular}{|c|c|c|c|}
\hline WP & BQE & Countries & $\begin{array}{l}\# \\
\text { Water } \\
\text { bodies }\end{array}$ \\
\hline 3.1 & Phytoplankton & $\begin{array}{l}\text { BE, CY, DE, DK, EE, ES, FI, } \\
\text { FR, GR, HU, IE, IT, LT, } \\
\text { LV, NL, NO, PL, PT, RO, } \\
\text { SE, UK }\end{array}$ & $2,063^{\mathrm{a}}$ \\
\hline 3.2 & Macrophytes & $\begin{array}{l}\text { BE, EE, FI, IE, LT, LV, NL, } \\
\text { NO, PL, RO, SE, UK }\end{array}$ & 1,571 \\
\hline 3.3 & $\begin{array}{l}\text { Benthic } \\
\text { invertebrates }\end{array}$ & $\begin{array}{l}\text { BE, DE, EE, LT, LV, NL, PL, } \\
\text { UK }\end{array}$ & 193 \\
\hline 3.4 & Fish & $\begin{array}{l}\text { DE, DK, EE, ES, FI, FR, IE, } \\
\text { IT, LT, LV, NO, PT, RO, } \\
\text { SI, SE, UK }\end{array}$ & 445 \\
\hline
\end{tabular}

The data were split into four Workpackages (WP), each representing a single Biological Quality Element (BQE)

a The phytoplankton database also contains chlorophyll a data from 6,532 water bodies in Europe

Table 2 Overview of the sampling campaign executed within the WISER project in 2009 and 2010

\begin{tabular}{llll}
\hline WP & BQE & Countries involved & $\begin{array}{l}\# \\
\text { Lakes }\end{array}$ \\
\hline 3.1 & Phytoplankton & $\begin{array}{l}\text { DE, DK, EE, ES, FI, FR, IT, } \\
\text { NO, PL, SE, UK }\end{array}$ & 29 \\
3.2 & Macrophytes & $\begin{array}{l}\text { DE, DK, EE, FI, FR, IT, NO, } \\
\text { PL, SE, UK }\end{array}$ & 28 \\
3.3 & $\begin{array}{l}\text { Benthic } \\
\text { invertebrates }\end{array}$ & $\begin{array}{l}\text { DE, DK, EE, FI, IE, IT, SE, } \\
\text { UK }\end{array}$ & 51 \\
3.4 & Fish & $\begin{array}{l}\text { DK, FI, FR, DE, IE, IT, NO, } \\
\text { SE, UK }\end{array}$ & 14 \\
\hline
\end{tabular}

Central-Baltic GIGs, but also included lakes and reservoirs in the Mediterranean and Eastern Continental GIGs.

Metrics included

The metrics tested for responses to eutrophication are given in Table $3 \mathrm{a}$ and comprise five different metrics for phytoplankton (Carvalho et al., 2012; Phillips et al., 2012), three different metrics for macrophytes (Kolada et al., 2011; Dudley et al., 2012), one multimetric index for benthic invertebrates (Böhmer et al., 2011; Pilotto et al., 2011) and two multimetric indices for fish (Argillier et al., 2012). 
Table 3 Overview of metrics for assessment of different Biological Quality Elements (BQEs) responding to (a) eutrophication pressure expressed as total phosphorus and (b) hydromorphological pressure expressed as water level fluctuations (winter drawdown) for macrophytes and as a stressor index for morphological modifications of lake shores for benthic invertebrates

\begin{tabular}{|c|c|c|}
\hline BQE & Metric & Metric description \\
\hline \multicolumn{3}{|l|}{ (a) } \\
\hline \multirow[t]{5}{*}{ Phytoplankton } & Chla & Chlorophyll $a(\mu \mathrm{g} / \mathrm{l})$ \\
\hline & PTI & Phytoplankton Trophic Index \\
\hline & FTI & Functional Traits Index (mean of SPI and MFGI) \\
\hline & $J^{\prime}$ & Evenness \\
\hline & $\begin{array}{l}\text { Cyano bloom } \\
\text { intensity }\end{array}$ & Cyanobacteria biovolume (mg/l) \\
\hline \multirow[t]{3}{*}{ Macrophytes } & ICM & Intercalibration Common Metric \\
\hline & EI & Ellenberg Index of taxonomic composition \\
\hline & $C_{\max }$ & Maximum growing depth of submerged macrophytes \\
\hline $\begin{array}{l}\text { Benthic } \\
\text { invertebrates }\end{array}$ & MMI & $\begin{array}{l}\text { Multimetric Index for intercalibration in the Central-Baltic GIG (including the single indices: } \\
\text { number of EPTCBO taxa, ASPT, \% ETO, \% Habitat preference lithal }\end{array}$ \\
\hline \multirow[t]{2}{*}{ Fish } & ELFI & European Lake Fish Index (multimetric of BPUE, CPUE and CPUE_OMNI) \\
\hline & NLFI & Nordic Lake Fish Index (multimetric of BPUE and BPUE_BENT) \\
\hline \multicolumn{3}{|l|}{ (b) } \\
\hline Macrophytes & WIc & Water level drawdown index for macrophytes \\
\hline \multirow{2}{*}{$\begin{array}{l}\text { Benthic } \\
\text { invertebrates }\end{array}$} & LIMCO & Littoral Invertebrate Multimetric Index based on Composite Sampling \\
\hline & LIMHA & Littoral Invertebrate Multimetric Index based on Habitat Specific Sampling \\
\hline
\end{tabular}

For explanation of the acronyms of single indices, see references in text

Comparison of regression strength and sensitivity for metrics tested for response to eutrophication

Linear regression models and $t$ tests of standardised ( $z$ transformed) data were used to compare regression strengths (correlation coefficient $r$ ) and response sensitivity (standardised regression slope $b 1$ ) of the metrics described above. All metrics were regressed against Total Phosphorus (TP) which provided an independent variable reflecting eutrophication pressure intensity in this analysis. The steps of the procedure applied in these analyses are:

- scatter plots were used to check the distribution of metric values along the $\log _{10}$-transformed TP $\left(\mu \mathrm{g} 1^{-1}\right)$ gradient

- if necessary, $\log _{10}$ transformation of the response metric was done to achieve linear relationships (see Table 4)

- TP and metric values were $z$-transformed $($ mean $=0, \mathrm{SD}=1)$

- a linear regression model was run on the $z$-transformed data using R (R Development Core Team, 2009)
- standardised slopes, slopes' standard error (SE) and adjusted $R^{2}$ values were derived (Table 5)

- slopes of all metrics were plotted on one figure (intercept $=0$ for all slopes due to standardisation)

- $t$ values and df (degrees of freedom) for pairwise comparisons of all metrics (55 pairs in total) were calculated according to Zar (1996), but with a simplified formula: $t=\frac{b_{1}-b_{2}}{s_{b_{1}-b_{2}}}$, where $b_{1}$ and $b_{2}$ are the standardised slopes of the two regressions and $s_{b 1-b 2}$ is the square root of the sums of squares of the standard errors of the two regression slopes (Zar, 1996, p. 353).

- critical t values were calculated for $P<0.05$, $P<0.01$ and $P<0.001$ given the degrees of freedom of the pairwise comparisons (done using the qt function in $R) ; P<0.001$ here is equivalent to the Bonferroni-corrected $P<0.05$ (=0.05/55)

- correlation coefficients were compared using the $R$ function r.test of the library psych (Revelle, 2012). Package 'psych', version 1.2.8. Procedures for Psychological, Psychometric, and Personality Research. http://personality-project.org/r/psych. 


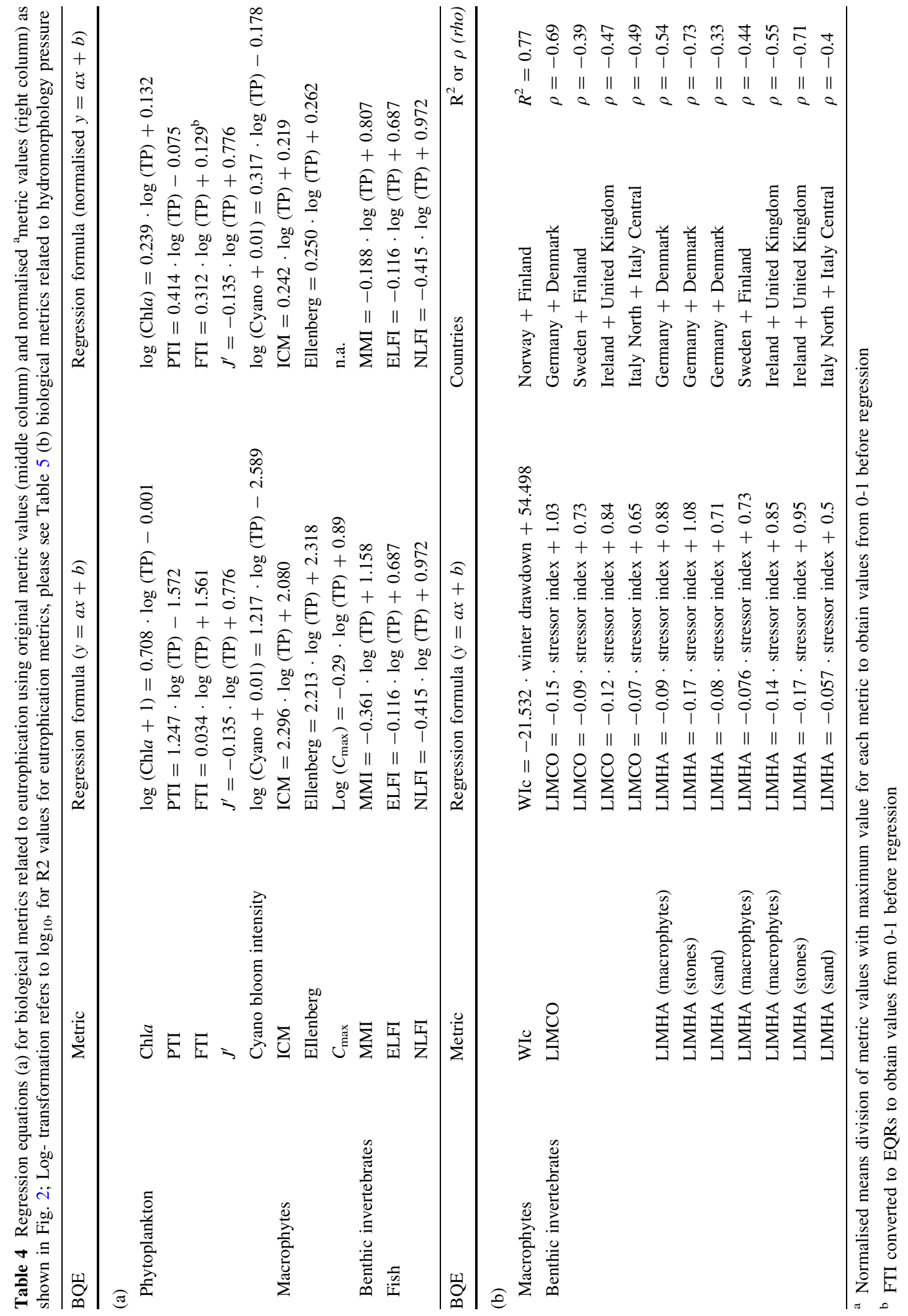


manual.pdf. Also available as an online calculation tool at http://www.vassarstats.net/rdiff.html.

The strength of the metric response to pressure expressed by the correlation coefficients $(r)$ and the sensitivity of the metric response expressed by the standardised slopes $\left(b 1^{*}\right)$ were used to rank the metric's performance. Rank orders were derived from pairwise comparisons and reflect the level of metric performance in the analysis. Ranks were calculated by summing up the number of other metrics that were significantly lower in correlation/slope (scoring +1 ) or higher (scoring -1 ) than the considered metric.

\section{Data and methods for biological metrics describing response to hydromorphological alterations}

The metrics related to hydromorphological pressures are a taxonomic composition index for macrophytes based on responses to water level fluctuations in hydropower reservoirs (Mjelde et al., 2012) and two multimetric indices for benthic invertebrates describing responses to morphological modifications of lake shores (Miler et al., 2012; Sandin \& Solimini, 2012) (Table 3b).

Macrophyte response to water level fluctuations (winter drawdown)

The dataset used in the water level fluctuation analysis included winter drawdown data as an indicator of water level regulation amplitude (see Hellsten, 2001). Winter drawdown was calculated as the average difference between the highest water level during OctoberDecember and the lowest level during the following April-May. The macrophyte data included in total 67 lakes; 29 Finnish lakes, 25 Norwegian lakes and 13 Swedish lakes. The data were used to establish the water level drawdown index (WIc) based on the sensitivity of aquatic macrophytes to winter drawdown of water level. A further regression was developed by selecting only lakes under hydropower production, leading to regulation amplitudes between 1 and $6 \mathrm{~m}$. All details are presented in Mjelde et al. (2012).

Littoral macroinvertebrate response to shoreline modifications

A sampling campaign of benthic invertebrates was conducted in the eulittoral zone of 51 lakes in order to produce a methodologically homogeneous dataset. The sampling campaign included lakes in seven countries sampled at shoreline sections representing three levels of hydromorphological degradation (unmodified, moderately modified and highly modified) (Miler et al., 2012). More specifically, benthic invertebrates were sampled in Germany (9 lakes), Denmark (2 lakes), Ireland (9 lakes), United Kingdom (3 lakes), Sweden (9 lakes), Finland (4 lakes) and Italy (15 lakes with eight lakes in the subalpine and seven lakes in the Mediterranean region). Hydromorphological pressures on lake shores were parameterised using the Lake Habitat Survey (LHS) method (Rowan et al., 2006; Rowan, 2008). Parameters obtained by the LHS method were used for the development of a stressor index which was needed to calibrate the developed biotic multimetric indices. The Littoral Invertebrate Multimetric index based on Composite samples (LIMCO) and the Littoral Invertebrate Multimetric index based on habitat samples (LIMHA) were developed separately for each of the four biogeographical regions Germany/Denmark, Ireland/United Kingdom, Sweden/Finland and Central Italy/Northern Italy. For more information see Miler et al. (2012).

\section{Statistical methods and data used for assessing uncertainty}

The statistical methods used for assessing uncertainty related to sampling, analysis and within-lake spatial variability for biological metrics are based on the harmonised sampling exercise and the WISERBUGS software. Further details are given in other articles (Clarke, 2012; Carvalho et al., 2012; Dudley et al., 2012; Sandin \& Solimini, 2012).

\section{Results}

The regression equations for the biological metric responses to eutrophication or to hydromorphological alterations are given in Table 4.

Strength and sensitivity of biological metrics for various $\mathrm{BQEs}$ tested for response to eutrophication

The regression plots with the metrics on a normalised scale are presented in Fig. 1. Statistical data for each 
regression used for the analyses of strength and sensitivity are presented in Table 5. The standardised regression curves are also plotted to illustrate the relative sensitivities in Fig. 2. The ranking of the metric's performance is given in Table 6 and shows which metrics are best to use for assessing the ecological status of European lakes where eutrophication is the dominant pressure. The strongest and/or most sensitive metrics are, for phytoplankton: chlorophyll, the taxonomic composition trophic index (PTI) and the functional traits index (FTI), for macrophytes: the intercalibration common taxonomic composition metric (ICM) and for fish: the Nordic lake fish index (NLFI) based on fish abundance and composition. Metrics with intermediate performance are the multimetric index for benthic invertebrates (MMI) used for intercalibration of national assessment methods in the Central-Baltic GIG, the Ellenberg index for macrophytes, which is sensitive to $\mathrm{TP}<80 \mu \mathrm{g} / \mathrm{l}$, and the Cyanobacteria bloom intensity metric (CYANO). The weakest and/or least sensitive metrics are phytoplankton evenness, the maximum colonisation depth for macrophytes $\left(C_{\max }\right)$ and the European Lake Fish Index (ELFI).

Thus, for phytoplankton, the metrics can be ranked in the following order according to their sensitivity to TP concentration: chlorophyll a, PTI, FTI, Cyano and Evenness. Similarly, for macrophytes, the order of metrics from the best to the worst are ICM, Ellenberg index and $C_{\max }$, although for the latter only the regression coefficient and not the slope could be compared (see Søndergaard et al., 2012 for more info). For fish, the Nordic Index (NLFI) performed considerably better than the European Index (ELFI).

Strength of biological metrics tested for response to hydromorphological alterations

\section{Macrophyte response to water level fluctuations (winter drawdown)}

The WIc index based on data from Norway and Finland showed a very strong relationship with winter drawdown in reservoirs with an $r^{2}$ of 0.77 (Fig. 3), indicating clear changes in the taxonomic composition along the pressure gradient. The class boundary for good ecological potential suggested that at a WIc value of -20 , corresponding to ca. $3.5 \mathrm{~m}$ winter drawdown is based on a clear threshold response for indicator taxa, for instance Isoëtes (Mjelde et al., 2012).

Littoral macroinvertebrate responses

to morphological shoreline modifications

The multimetric index LIMCO (based on the composite invertebrate samples) was significantly correlated with the stressor index on shoreline modifications in all the four biogeographic regions covered by the dataset (Table 4b). The strongest correlation was shown for the region of Germany and Denmark $(\rho=-0.69)$, followed by the Irish/UK region and the Italian region $(\rho=-0.47$ and -0.49 , respectively), whereas the correlation for the Northern region with Sweden and Finland was the weakest ( $\rho=-0.39$ ). The multimetric index LIMHA (based on habitat-specific samples) showed the strongest correlations for stony habitats for the regions Germany and Denmark $(\rho=-0.73)$ and Ireland and United Kingdom $(\rho=-0.71)$, intermediate correlation strength in habitats with macrophytes for Germany and Denmark $(\rho=-0.54)$, Ireland and United Kingdom $(\rho=-0.55)$ and Sweden and Finland $(\rho=$ $-0.44)$ and the weakest correlations in sandy habitats in Germany and Denmark $(\rho=-0.33)$ and in Central and Northern Italy $(\rho=-0.4)$. Further details are given in Miler et al. (2012).

Uncertainty related to sampling, analysis and within-lake spatial and temporal variability

Within-lake variability caused by natural spatial variation, as well as variability related to sampling and sample processing, was low for phytoplankton, especially for the metrics chlorophyll a, PTI, MFGI (part of FTI) and Cyano bloom intensity with subsampling as the most important variance factor $(<15 \%$, see Table 7$)$. The SPI (size phytoplankton index) and Evenness metrics $\left(J^{\prime}\right)$ had considerably higher variability (ca. 30-35\%), the analyst being the most important variance component. For phytoplankton in general, the most important variance component was temporal variability, both seasonal and interannual (Thackeray et al., 2011). The uncertainty in the mean value of the metrics used for assessing ecological status can be reduced by adopting the recommended minimum sampling frequency of 6-12 samples for phytoplankton assessment given in 


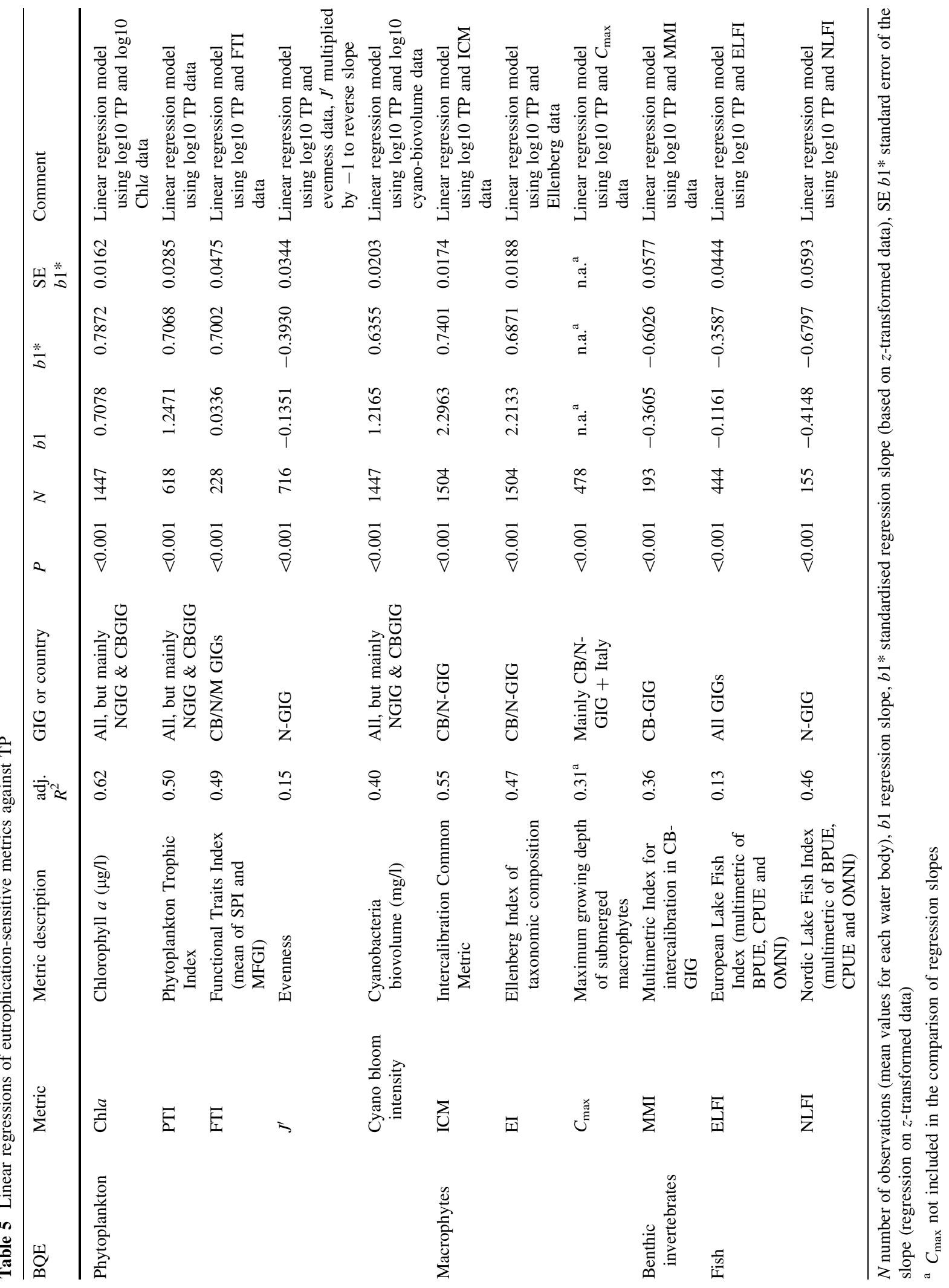



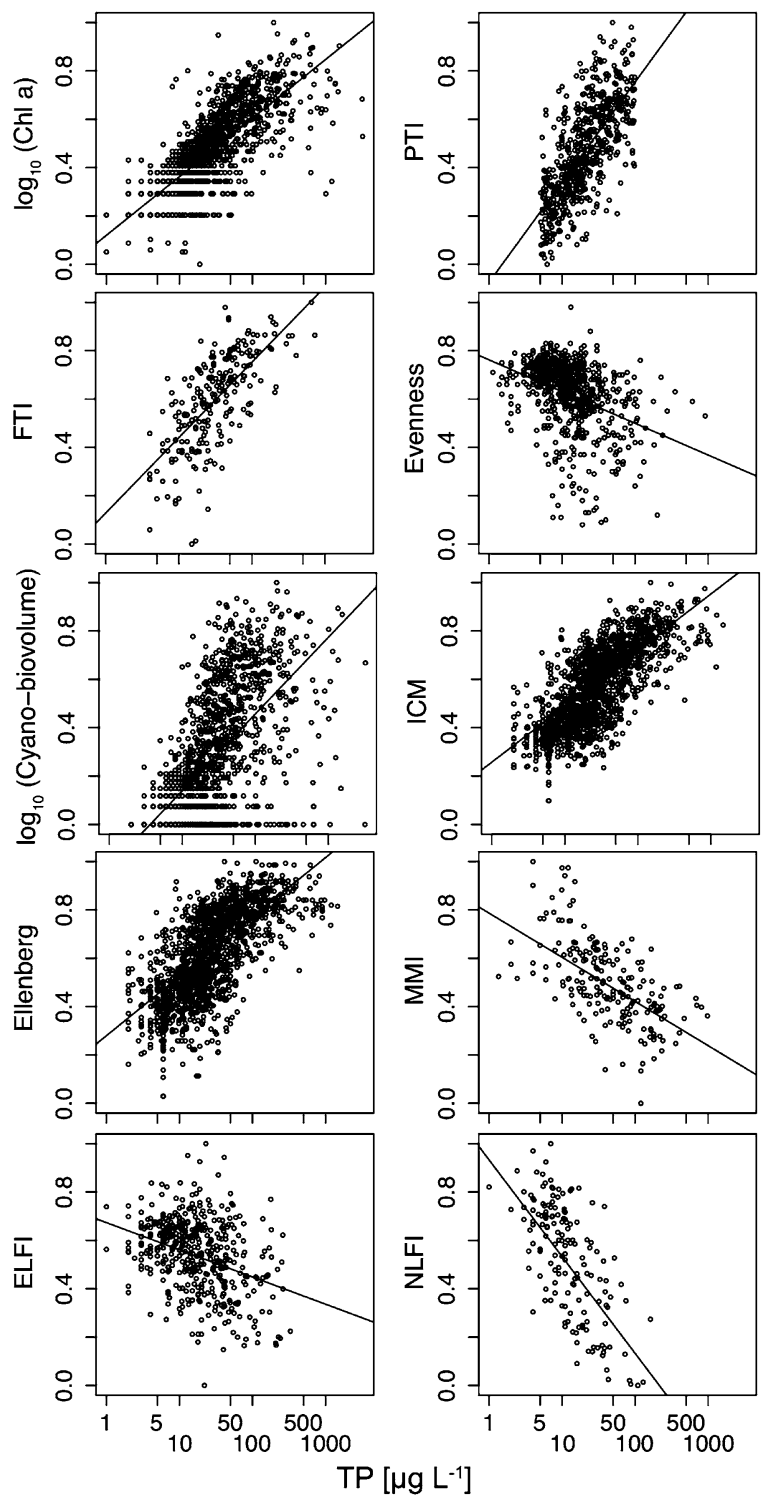

Fig. 1 Individual regressions of ten lake metrics representing all BQEs responding to eutrophication pressure, expressed as total phosphorus. All metrics normalised (division by maximal value) or recalculated as EQR (only FTI). Metric acronyms are explained in Table 3

Carvalho et al. (2012). For lake macrophytes, metric variability averaged $25-30 \%$ with station as the major variance component. Thus, for macrophyte metrics it is necessary to sample several stations or increase the station area to reduce uncertainty in ecological status assessment. For littoral benthic invertebrates, the major within-lake variability was between sites, but this was partly (8-12\%) due to consistent effects of the morphological pressure expressed by habitat modification type. For fish, the major variance components were depth stratum (numbers), referring to benthic gill-nets set in successive 3-m depth zones, and variability between individual nets (biomass). This variability reflects substantial spatial heterogeneity of fish distribution, caused in part not only by abiotic factors such as oxygen, temperature and light, but also by natural behavioural differences between species, including schooling.

\section{Discussion and conclusions}

The WFD is a major challenge to freshwater ecologists and managers requiring them to develop robust biological monitoring schemes with a quantified understanding of how lakes respond to pressures and how to define the uncertainty of the final classification results. A number of gaps for lake metrics for particular BQEs, for instance fish and algal bloom metrics in relation to eutrophication, and how lake biology responds to hydromorphological pressures have been addressed in the WISER project. The results presented here are the first comparative and quantitative assessment of metrics within and across BQEs responding to the two most widespread pressures on lakes in Europe: eutrophication and hydromorphological alteration (EEA-ETC, 2012).

Why do the eutrophication metrics show different strength and sensitivity to total phosphorus?

The analyses of strengths and sensitivity of the various metrics presented in this paper revealed a large variation in quality from very strong to quite weak correlations to TP. This difference can be ascribed to multiple environmental factors. Phytoplankton, being primary producers, exhibits the most direct response to TP concentrations in the water column. By contrast, benthic invertebrates and fish respond indirectly to TP via secondary effects of eutrophication, either as consumers of phytoplankton-derived organic matter, through responses to associated changes in light and oxygen conditions, or due to habitat complexity linked to macrophytes. Macrophytes are more intermediate, being slower growing primary producers that rely mainly on sediment sources of nutrients and are affected by nitrate availability (James et al., 2005; 


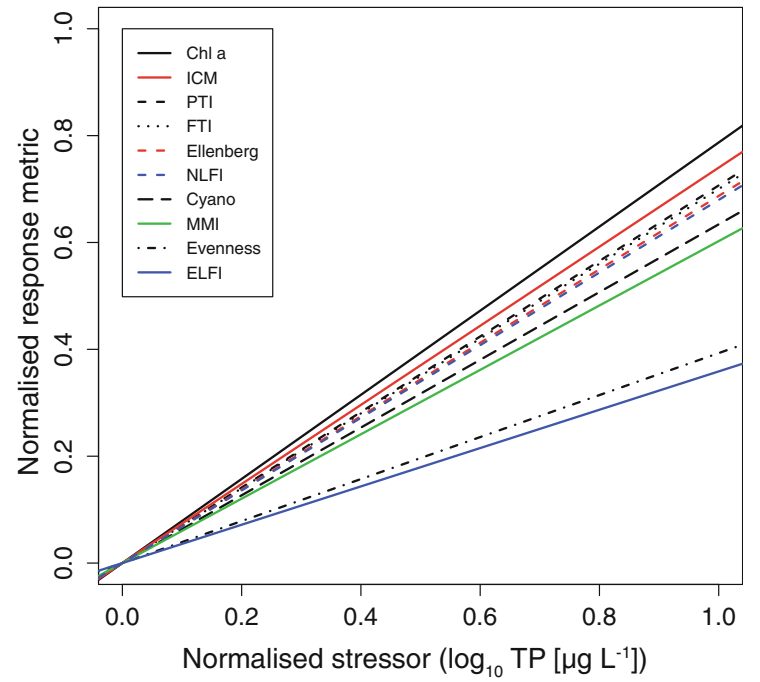

Fig. 2 Normalised regression lines of the same metrics as shown in Fig. 1

Raun et al., 2010). Macrophytes are also very sensitive to changes in light conditions, such as increased phytoplankton biomass, water colour and turbidity. These factors can explain why the maximum growing depth for macrophytes $\left(C_{\max }\right)$ showed a relatively weak response to $\mathrm{TP}$, as this metric can be greatly affected by water colour and turbidity, as well as by sediment conditions. The performance of such metrics will greatly improve if these other factors are included

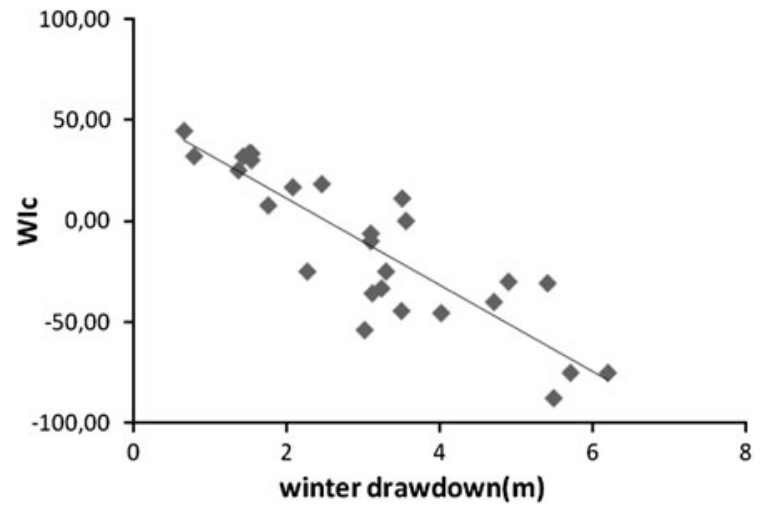

Fig. 3 Macrophyte response to water level fluctuations given as winter drawdown in metres. WIc is the macrophyte water level fluctuations index

in the regression model (Søndergaard et al., 2012). The ICM for macrophytes performs better because it is based on TP optima for the various macrophyte taxa. Uncertainty in the ICM is low compared to $C_{\max }$, although both metrics are calculated from data representing the same sampling effort (Dudley et al., 2012). Even within the phytoplankton, metric strength can vary greatly due to more complex responses that may be affected not just by TP (c.f. evenness and cyanobacteria metrics compared with chlorophyll and PTI metrics). Cyanobacteria are particularly sensitive to water colour, flushing rate (Carvalho et al., 2011) and mixing, and are affected also by nitrogen (Dolman

Table 6 Comparison of correlation coefficients $(r)$ of metrics representing four Biological Quality Elements (BQE) ( $r$ is equivalent to the standardised regression slopes $\left.\left(b_{1}^{*}\right)\right)$

\begin{tabular}{|c|c|c|c|c|c|}
\hline Metric & BQE & $|r|(=|b 1 *|)$ & Rank order $r$ & Rank order $b_{1}^{*}$ & Mean rank order \\
\hline Chla & Phytoplankton & 0.787 & 7 & 4 & 5.5 \\
\hline ICM & Macrophytes & 0.740 & 5 & 3 & 4 \\
\hline PTI & Phytoplankton & 0.707 & 3 & 2 & 2.5 \\
\hline FTI & Phytoplankton & 0.700 & 2 & 2 & 2 \\
\hline NLFI & Fish & 0.680 & 2 & 2 & 2 \\
\hline Ellenberg & Macrophytes & 0.687 & 2 & 1 & 1.5 \\
\hline MMI & Benthic invertebrates & 0.603 & 0 & 1 & 0.5 \\
\hline Cyano & Phytoplankton & 0.634 & 0 & 0 & 0 \\
\hline$C_{\max }$ & Macrophytes & 0.562 & -2 & - & -2 \\
\hline Evenness & Phytoplankton & 0.393 & -9 & -7 & -8 \\
\hline ELFI & Fish & 0.359 & -9 & -7 & -8 \\
\hline
\end{tabular}

Rank orders were derived from pairwise comparisons and reflect the level of metric performance in the analysis. Ranks were calculated by summing up the number of other metrics that were significantly lower in correlation/slope $($ scoring +1$)$ or higher (scoring -1) than the considered metric. All significances at $P<0.05$, corrected for multiple pairwise comparisons using the Bonferroni method 
Table 7 Metric precision given as proportion of within-lake variability of total variance (i.e. within- and between-lake variability), and major within-lake variance components for three BQEs

\begin{tabular}{|c|c|c|c|}
\hline BQE & Metric & $\begin{array}{l}\text { Within-lake } \\
\text { variance (excluding } \\
\text { temporal variability }{ }^{\mathrm{a}} \text { ) }\end{array}$ & $\begin{array}{l}\text { Major variance } \\
\text { component (excluding } \\
\text { temporal variability }{ }^{\mathrm{a}} \text { ) }\end{array}$ \\
\hline \multirow[t]{6}{*}{ Phytoplankton $^{\mathrm{a}}$} & Chl- $a$ & 0.04 & Sub-sampling \\
\hline & PTI & 0.12 & Sub-sampling \\
\hline & SPI (part of FTI) & 0.35 & Analyst \\
\hline & MFGI (part of FTI & 0.14 & Sub-sampling \\
\hline & $J^{\prime}$ (Evenness) & 0.31 & Analyst \\
\hline & Cyano blooms intensity & 0.06 & Sub-sampling \\
\hline \multirow[t]{3}{*}{ Macrophytes } & $\mathrm{ICM}$ & 0.28 & Station \\
\hline & Ellenberg Index & 0.26 & Station \\
\hline & $C_{\max }$ & 0.30 & Station \\
\hline \multirow[t]{4}{*}{ Benthic invertebrates } & Evenness & $0.73^{\mathrm{b}}$ & Station \\
\hline & NTaxa & $0.37^{\mathrm{b}}$ & Station \\
\hline & NTaxa EPTCBO (part of MMI) & $0.44^{\mathrm{b}}$ & Station \\
\hline & \%POM_HabPref (part of MMI) & $0.52^{\mathrm{b}}$ & Station \\
\hline \multirow[t]{2}{*}{ Fish } & BPUE $(\log 10)$ (part of ELFI) & 0.999 & Depth stratum \\
\hline & CPUE (part of ELFI and NLFI) & 0.962 & Single gillnets \\
\hline
\end{tabular}

Metrics with the lowest within-lake variance are the most precise whole-lake metrics. See Table 3 and text for explanation of metrics

${ }^{\text {a }}$ For temporal variability of phytoplankton, see Carvalho et al. (2012)

b Includes within-lake variance of $8-12 \%$ due to margin modification type (U, S, H)

et al., 2012), whereas the PTI is specifically calibrated to TP (Phillips et al., 2012). Moreover, in shallow lakes cyanobacteria are substituted by green algae at the highest nutrient levels (Jensen et al., 1994).

Other pressures may also override the effects of nutrient enrichment. Examples of metrics being largely affected by other pressures are the benthic invertebrates multimetric index (MMI), where morphological degradation was more important than TP, and the inclusion of morphological degradation raised Pearson's $R$ from 0.60 for TP alone to 0.73 for the combined pressure (Böhmer et al., 2011). This multimetric index was primarily developed for strong correlations with the national assessment methods in the Central-Baltic GIG and for responsiveness to morphological alterations, and showed intermediate sensitivity to TP when compared with the other metrics for other BQEs (Table 6). Also, the fish metrics are largely affected by a series of other environmental factors, such as lake morphometry, as well as availability of substrate feasible for spawning, in addition to other human pressures, such as climate change (temperature) or stocking and fishing (Jeppesen et al., 2010; Argillier et al., 2012).
An additional reason for the different performance of the various metrics and BQEs is variation in the length of the pressure gradient in the separate $B Q E$ datasets, especially if data in the lower or upper ends of the gradient are few, or missing. Variation in the lake types or regions covered by the dataset may be another reason, rendering some metrics more applicable for certain types or regions. For example, the Fish multimetric index for the Northern region (NLFI) performs better than the European Lake Fish Index (ELFI), which can be due to a more heterogenous dataset used for the ELFI index, having larger variability of other environmental factors, thereby obscuring the TP pressure signal. Also, the Phytoplankton Evenness metric performs better in the Northern region than in other regions of Europe (Mischke et al., 2011).

Applications of the WISER metrics for assessing eutrophication impacts in lakes

Total Phosphorus (TP) is used in this paper as a widely recognised general proxy of eutrophication pressure, because it is generally demonstrated to be the most 
important nutrient responsible for lake eutrophication (e.g. Phillips et al., 2008). Recovery from eutrophication requires management measures to reduce the external P-load to lakes from their catchments. However, as outlined in the introduction, TP alone cannot provide sufficient information on the ecological status of lakes impacted by eutrophication. A robust assessment of ecological status requires the full suite of BQEs, as they provide information on different aspects of lake eutrophication: While the phytoplankton primarily reflects the pelagic zone, macrophytes and benthic invertebrates respond to changes in the littoral zone, and fish integrate eutrophication effects across the whole system. Given their different generation times and life spans, responses also represent nutrient impacts over different time periods with phytoplankton representing more immediate responses to nutrient supply, whilst macrophytes and fish reflect nutrient pressures over years. In very shallow lakes, eutrophication impacts may be most immediate or pronounced in terms of macrophyte abundance and composition, which may buffer the impacts on phytoplankton (Moss, 1990; Scheffer et al., 1993; Jeppesen et al., 1998).

The BQEs also reflect a range of eutrophication impacts, not just a response to TP. As indicated earlier, impacts include indirect responses to changing light or nitrogen concentrations affecting phytoplankton and macrophytes, oxygen conditions affecting invertebrates and fish, or sediment quality affecting macrophytes and benthic invertebrates, as well as the spawning habitat for fish. Thus, although the various BQEs and metrics within the BQEs in this study all relate to the same pressure (indicated by TP), they should not be considered as redundant.

Some of the best metrics developed in WISER have already been successfully used as common metrics in the intercalibration of national assessment methods (Table 8). A combination of chlorophyll $a$ and the new WISER PTI metric for phytoplankton taxonomic composition (Phillips et al., 2012) was used as a common metric in the Northern and Central-Baltic GIGs (Lyche-Solheim et al., 2011; Phillips et al., 2011). Also, the macrophyte ICM was used as a common metric in the Northern GIG (Hellsten et al., 2011). The benthic invertebrate MMI was used as a common metric in the Central-Baltic GIG after combining several pressures in addition to $\mathrm{TP}$, including morphological shoreline modifications and land-use in near lake surroundings (Böhmer et al., 2011, Pilotto et al., 2011). The MMI had a better response to these combined pressures than to TP alone, as outlined above.

Although the Cyanobacteria bloom metric had only intermediate performance, it was adopted by countries without national methods for blooms (e.g. Norway and UK, see Lyche-Solheim et al., 2011) to fulfil the WFD requirement for bloom metrics in addition to biomass and composition metrics. An additional advantage of the Cyanobacteria bloom metric is its clear link to human health and thus to ecosystem services concerning the quality of recreational waters (WHO, 1999). The phytoplankton FTI also performed well and reflects functional aspects of the phytoplankton community (Carvalho et al., 2012), which fills an ecologically relevant gap in phytoplankton assessments. The Northern Lake Fish index (NLFI) has a great potential for use in countries lacking assessment methods for fish in lakes or intending to improve their current national methods for this BQE. Adaptation of the metrics may be needed to account for regionspecific or type-specific conditions before adoption into national classification systems.

How to assess impacts of hydromorphological pressures on lakes?

The work on lakes in WISER has resulted in new metrics for the two most sensitive BQEs for hydromorphological pressures, namely macrophytes and benthic invertebrates. The macrophyte water level fluctuation metric (WIc) has a very strong response to hydrologic disturbance in Nordic regulated lakes used for hydropower production (Mjelde et al., 2012), and may be used to assess the ecological potential in heavily modified lakes. Winter drawdown was used as a proxy for ice effects on the littoral zone. However, whereas winter drawdown was commonly used in hydropower reservoirs in previous years, the normal practice nowadays is hydropeaking, which depends on electricity demand and causes more frequent water level fluctuations also in the growing season for macrophytes. Thus, the metric developed in WISER based on available data from previous years should be further developed taking hydropeaking into account. Data from Alpine reservoirs should also be included.

The benthic invertebrate multimetric indices LIM$\mathrm{CO}$ and LIMHA show good correlations with the 
morphological stressor index (Table 4b, Miler et al., 2012), especially for the LIMCO index in the biogeographical region of Germany/Denmark $(\rho=-0.69)$, and for the LIMHA index for stony habitats in two regions: Germany and Denmark $(\rho=-0.73)$ and Ireland and United Kingdom ( $\rho=-0.71)$ (Table 4b).

Effects of morphological alterations to lake shores on benthic invertebrates can be assessed at whole-lake level by interpolation of site-specific biological scores using physical habitat surveys of the lakeshore sections in-between the biological sampling sites. Results of the physical habitat surveys can be recalculated into the stressor index correlated to the biological metrics. This enables estimation of the LIMCO and LIMHA scores for the whole shoreline of a lake. Further sampling is needed to validate these new multimetric indices, as well as to improve their correlations with the morphological pressure.

Metric uncertainty and implications for sampling design and monitoring

The uncertainty analyses illustrate the importance of sampling design to obtain an adequate level of confidence in classification results. For phytoplankton, the major source of uncertainty is temporal variability, both seasonal and inter-annual (Thackeray et al., 2011), while other sources of uncertainty are minor for the best performing metrics (Table 7). Thus, the sampling design for phytoplankton should ensure an adequate sampling frequency, including at least 6-12 samples (Carvalho et al., 2012) from the pelagic euphotic zone, with higher frequency in eutrophic lakes, especially at recreationally important sites where there is a need to monitor potentially harmful blooms. Standard methods and training should be used for sampling and analyses.

Lakes have large variability in littoral habitats that are important to take into account when sampling littoral BQEs, such as macrophytes and benthic invertebrates. An adequate number of habitat-specific sampling sites should be covered to ensure a proper assessment for these BQEs (Dudley et al., 2012; Sandin \& Solimini, 2012). Macrophyte field methods should be based on transects covering all depth zones and different habitats. The assessment of impacts of shoreline modifications on benthic invertebrates should be based on composite or habitat-specific sampling at various stations representing the whole range of morphological shoreline modifications. Fish sampling must be designed to cover all the depth strata in a lake with a sufficient number of gill nets following the CEN standard (CEN, 2005) (Lauridsen et al., 2008). Hydro-acoustic methods can also help to improve confidence and cost-efficiency of fish monitoring and to avoid destructive sampling (Emmrich et al., 2012a, b).

\section{Conclusions and future challenges}

The WISER work on lakes has succeeded in developing a range of metrics for phytoplankton, macrophytes, benthic invertebrates and fish in close dialogue with the WFD working group ECOSTAT and its intercalibration process organised under the common implementation strategy (CIS). Several of these metrics show a clear response to eutrophication pressure and have been used as common metrics in the intercalibration work. Other metrics have been adopted as national metrics, or may be adopted in countries lacking methods for certain BQEs or intending to improve their existing methods. The evaluation of strength of the eutrophication-related metrics in this paper is based solely on TP. It is, therefore, not surprising that primary producers, particularly phytoplankton, have well performing metrics. However, it is not only the metrics responding most strongly to $\mathrm{TP}$ that should be used for assessment of lake eutrophication impacts, as metric strength here is based on the relationship for a large population of lakes, whereas in the WFD they are applied to individual lakes. At some of these sites, some of the less strong metrics (cyanobacteria blooms, European lake fish index), which are still significantly related to eutrophication, may be particularly important and have a much stronger relevance to sustainable water use (the ultimate objective of the WFD). Moreover, the use of several BQEs and/or metrics within a BQE to assess status can also provide a more confident assessment, with a greater weight of evidence of the overall lake impacts of eutrophication, including all parts of the lake and various time scales. Thus, using several BQEs and not only one (e.g. phytoplankton chlorophyll a) potentially overcomes some of the problems of unexplained variability in the relationships between each of the individual metrics and TP, to which trophic cascade effects, lake specific factors (e.g. morphometry) or other pressures presumably contribute. 
Table 8 Overview of common metrics and correlations with national methods for different common lake types in different geographical intercalibration groups (GIGs)

\begin{tabular}{|c|c|c|c|c|c|c|c|c|c|}
\hline \multirow{2}{*}{$\begin{array}{l}\text { BQE } \\
\text { Phytoplankton }\end{array}$} & \multirow{3}{*}{$\begin{array}{l}\text { GIG and country } \\
\text { Alpine GIG } \\
\text { AT }\end{array}$} & \multicolumn{6}{|c|}{$\begin{array}{l}\mathrm{R} \text { Pearson between national } \mathrm{EQRs} \text { and common metrics } \\
\text { for different common lake types }\end{array}$} & & Common metrics \\
\hline & & \multicolumn{4}{|c|}{ L-AL3 } & \multicolumn{3}{|c|}{ L-AL4 } & \multirow{5}{*}{$\begin{array}{l}\text { Average of each national } \\
\text { methods EQRs (Pseudo- } \\
\text { Common Metric) }\end{array}$} \\
\hline & & \multicolumn{4}{|l|}{0.96} & \multicolumn{3}{|l|}{0.94} & \\
\hline & $\mathrm{DE}$ & \multicolumn{4}{|l|}{0.93} & \multicolumn{3}{|l|}{0.96} & \\
\hline & IT & \multicolumn{4}{|l|}{0.95} & \multicolumn{3}{|l|}{0.95} & \\
\hline & SI & \multicolumn{4}{|l|}{0.96} & \multicolumn{3}{|l|}{0.94} & \\
\hline & CB GIG & \multicolumn{4}{|l|}{ LCB1 } & \multicolumn{3}{|l|}{ LCB2 } & \multirow{12}{*}{$\begin{array}{l}\text { Average of normalised } \\
\text { chlorophyll } a \mathrm{EQR} \text { and } \\
\text { phytoplankton trophic } \\
\text { index (PTI) EQR }\end{array}$} \\
\hline & $\mathrm{BE}$ & \multicolumn{4}{|l|}{0.79} & \multicolumn{3}{|l|}{0.97} & \\
\hline & $\mathrm{DE}$ & \multicolumn{4}{|l|}{0.79} & 0.93 & & & \\
\hline & DK & 0.74 & & & & 0.73 & & & \\
\hline & $\mathrm{EE}$ & 0.53 & & & & 0.85 & & & \\
\hline & FR & 0.75 & & & & 0.83 & & & \\
\hline & IE & 0.80 & & & & 0.89 & & & \\
\hline & LT & 0.48 & & & & 0.76 & & & \\
\hline & LV & 0.69 & & & & 0.72 & & & \\
\hline & NL & 0.81 & & & & 0.69 & & & \\
\hline & PL & 0.91 & & & & 0.90 & & & \\
\hline & UK & 0.83 & & & & 0.88 & & & \\
\hline & NOR GIG & LN1 & LN2a & LN2b & LN3a & LN5 & LN6a & LN8a & Average of normalised \\
\hline & FI & 0.94 & 0.69 & 0.86 & 0.89 & 0.94 & 0.80 & 0.89 & chlorophyll $a \mathrm{EQR}$ and \\
\hline & IE & 0.90 & 0.67 & & 0.87 & & & 0.93 & index (PTI) EQR \\
\hline & NO & 0.94 & 0.86 & 0.87 & 0.91 & 0.96 & 0.86 & 0.93 & \\
\hline & SE & 0.86 & 0.57 & & 0.91 & 0.81 & 0.61 & 0.87 & \\
\hline & UK & 0.94 & 0.85 & 0.84 & 0.84 & & & 0.89 & \\
\hline Macrophytes & Alpine GIG & All tyl & & & & & & & \\
\hline & AT & 0.74 & & & & & & & Average of each national \\
\hline & FR & 0.83 & & & & & & & methods EQRs (Pseudo- \\
\hline & $\mathrm{DE}$ & 0.86 & & & & & & & \\
\hline & IT & 0.74 & & & & & & & \\
\hline & SI & 0.83 & & & & & & & \\
\hline & CB GIG & All tyl & & & & & & & \\
\hline & $\mathrm{BE}$ & 0.63 & & & & & & & Average of each national \\
\hline & $\mathrm{DE}$ & 0.65 & & & & & & & methods EQRs (Pseudo- \\
\hline & DK & 0.80 & & & & & & & \\
\hline & $\mathrm{EE}$ & 0.74 & & & & & & & \\
\hline & LT & 0.64 & & & & & & & \\
\hline & LV & 0.61 & & & & & & & \\
\hline & NL & 0.83 & & & & & & & \\
\hline & PL & 0.76 & & & & & & & \\
\hline & UK & 0,67 & & & & & & & \\
\hline & NOR GIG & All tyl & & & & & & & \\
\hline & FI & 0.62 & & & & & & & Lake macrophyte \\
\hline & IE & 0.72 & & & & & & & intercalibration common \\
\hline & NO & 0.91 & & & & & & & metric (ICN) \\
\hline & SE & 0.67 & & & & & & & \\
\hline & UK & 0.87 & & & & & & & \\
\hline
\end{tabular}


Table 8 continued

\begin{tabular}{|c|c|c|c|c|}
\hline BQE & GIG and country & \multicolumn{2}{|c|}{$\begin{array}{l}\text { R Pearson between national EQRs and common metrics } \\
\text { for different common lake types }\end{array}$} & Common metrics \\
\hline \multirow[t]{14}{*}{ Benthic invertebrates } & ALP GIG & \multicolumn{2}{|l|}{ All types } & \\
\hline & $\mathrm{DE}$ & \multicolumn{2}{|l|}{0.76} & Weighted average of Fauna \\
\hline & SI & \multicolumn{2}{|l|}{0.94} & $\begin{array}{l}\text { index, taxa richness, } \\
\text { reproduction strategy (r/k), } \\
\% \text { feeding type gatherer }\end{array}$ \\
\hline & CB GIG & & & \\
\hline & BE-FL & \multicolumn{2}{|l|}{0.56} & \multirow{7}{*}{$\begin{array}{l}\text { Weighted average of } \\
\text { normalised values of } \\
\text { number of EPTCBO taxa, } \\
\text { ASPT, \% ETO, \% Habitat } \\
\text { preference lithal (MMI) }\end{array}$} \\
\hline & $\mathrm{DE}$ & \multicolumn{2}{|l|}{0.63} & \\
\hline & $\mathrm{EE}$ & \multicolumn{2}{|l|}{0.63} & \\
\hline & LT & \multicolumn{2}{|l|}{0.36} & \\
\hline & NL & \multicolumn{2}{|l|}{0.70} & \\
\hline & UK & \multicolumn{2}{|l|}{0.43} & \\
\hline & NOR GIG ACID & \multicolumn{2}{|l|}{ All types } & \\
\hline & SE & \multicolumn{2}{|l|}{0.45} & \multirow{3}{*}{$\begin{array}{l}\text { Average of each national } \\
\text { methods EQRs (Pseudo- } \\
\text { Common Metric) }\end{array}$} \\
\hline & UK & \multicolumn{2}{|l|}{0.66} & \\
\hline & NO & \multicolumn{2}{|l|}{0.75} & \\
\hline \multirow[t]{4}{*}{ Fish } & ALP GIG & \multicolumn{2}{|l|}{ All types } & \\
\hline & AT & \multicolumn{2}{|l|}{0.97} & \multirow{3}{*}{$\begin{array}{l}\text { Average of each national } \\
\text { methods EQRs (Pseudo- } \\
\text { Common Metric) }\end{array}$} \\
\hline & $\mathrm{DE}$ & \multicolumn{2}{|l|}{0.97} & \\
\hline & SI & \multicolumn{2}{|l|}{0.84} & \\
\hline \multirow[t]{10}{*}{ Phytobenthos } & Cross GIG & High alkalinity type & Moderate alkalinity type & \\
\hline & $\mathrm{BE}$ & 0.88 & 0.89 & Trophic Index (TI) \\
\hline & $\mathrm{DE}$ & \multicolumn{2}{|l|}{0.77} & \\
\hline & FI & & 0.90 & \\
\hline & IE & 0.89 & 0.77 & \\
\hline & PL & 0.80 & & \\
\hline & SE & 0.63 & 0.74 & \\
\hline & UK & 0.94 & 0.87 & \\
\hline & SI & 0.94 & & \\
\hline & $\mathrm{HU}$ & 0.87 & & \\
\hline
\end{tabular}

Common metrics highlighted in bold are those developed by WISER and included in this paper. For details, see https://circabc.europa. $\mathrm{eu} / \mathrm{w} / \mathrm{browse} / \mathrm{c} 48010 \mathrm{c} 0-863 \mathrm{~b}-49 \mathrm{e} 6-8 \mathrm{f1a}-22 \mathrm{da} 029 \mathrm{~cd} 93 \mathrm{~b}$

Thus in concert, the four BQEs provide a more holistic picture of how eutrophication impacts a particular lake, and whether the problems mainly occur in the littoral areas or also affect off-shore pelagic waters. Only weak metrics that do not show a significant response to a pressure or do not provide additional evidence of eutrophication impacts should be abandoned.

New metrics have also been developed to assess impacts of hydromorphological pressures on lakes, focusing on the most sensitive BQEs for such pressures: macrophytes and littoral benthic invertebrates. For macrophytes, further work is needed to explore the consequences of hydropeaking in hydropower reservoirs, as well as the consequences of water level stabilisation in more productive lakes expanding the gradient of impact. Furthermore, macrophyte metrics should be developed to assess the impacts of morphological shoreline alterations to complement the benthic invertebrates multimetric indices. For benthic invertebrates, the influence of other environmental factors on the two metrics LIMCO and LIMHA and on their correlation with the morphological shoreline modification pressure should be further investigated based on more extensive datasets also covering other countries in Europe. Moreover, these indices should also be linked with the MMI, which was used for the intercalibration in the 
CB-GIG and proven to respond to hydromorphology and eutrophication in 11 countries.

Concerning the impacts of multiple pressures there is a need to assess how the responses to eutrophication and hydromorphological alterations will be affected by climate change, including related changes in the status of invasive species, and how they interact with the other BQEs. Climate change impacts on fish and their cascading effects have already been studied to some extent in WISER (Jeppesen et al., 2010, 2012). The major results are that cold-water species like Arctic char are pushed further north and towards higher altitudes, while warm-water species like many cyprinids increase in dominance and widen their biogeographical range. Warm lakes are usually dominated by small-sized individuals due to an increase in juvenile fish, whereas in cold lakes the relative proportion of large-sized fish increases (Emmrich et al., 2011). This may have cascading effects on phytoplankton as well as on other metrics used in WFD assessments (Jeppesen et al., 2010).

For biology to remain at the forefront of WFD implementation, and in the future revision of the Directive, it is essential that the metrics used in the national assessment systems in the different countries are well suited for lake management purposes. In Europe today 93 assessment methods for lakes are used in 24 countries, ranging from excellent to quite weakly performing metrics (Brucet et al., 2013). This situation cannot persist, since weak metrics provide a poor justification for the programme of measures intended to restore European lakes back to good status and prevent deterioration. The application of the betterperforming metrics presented here may be part of the way forward to improve the quality and comparability of national assessment systems across Europe. We also encourage further work that seeks to develop ecological indicators that are currently not part of WFD requirements, such as zooplankton (Caroni \& Irvine, 2010; Jeppesen et al., 2011), and that the four existing $\mathrm{BQEs}$ are further evaluated from an integrated ecosystem perspective (Moss, 2008). Sector authorities, the public and politicians are more likely to accept the use of biological indicators as a basis for decisions on costly management measures to reduce human impacts on lakes, if the links between these indicators and ecosystem services can be convincingly demonstrated. This is another important challenge for new research projects in the years to come.
Acknowledgments The paper is a result of the project WISER (Water bodies in Europe: Integrative Systems to assess Ecological status and Recovery) funded by the European Union under the 7th Framework Programme, Theme 6 (Environment including Climate Change) (contract No. 226273). We would like to thank Birger Skjelbred, Jannicke Moe and Bernard Dudley for assistance with data management and extraction, and a special thanks goes to all the data providers, as stated also in the individual BQE papers in this issue. We also thank the reviewer for helpful comments to the manuscript.

Open Access This article is distributed under the terms of the Creative Commons Attribution License which permits any use, distribution, and reproduction in any medium, provided the original author(s) and the source are credited.

\section{References}

Argillier, C., S. Caussé, M. Gevrey, S. Pédron, J. De Bortoli, S. Brucet, M. Emmrich, E. Jeppesen, T. Lauridsen, T. Mehner, M. Olin, M. Rask, P. Volta, I. J. Winfield, F. Kelly, T. Krause, A. Palm, \& K. Holmgren, 2012. Development of a fish-based index to assess the eutrophication status of European lakes. Hydrobiologia, this issue. doi:10.1007/ s10750-012-1282-y.

Birk, S., W. Bonne, A. Borja, S. Brucet, A. Courrat, S. Poikane, A. Solimini, W. van de Bund, N. Zampoukas \& D. Hering, 2012. Three hundred ways to assess Europe's surface waters: an almost complete overview of biological methods to implement the Water Framework Directive. Ecological Indicators 18: 31-41.

Böhmer, J., K. Arbaciauskas, G. Porst, B. Reeze, H. Timm, W. Gabriels, M. Golub, R. Benstead, P. Wiberg-Larsen, M. Gevrey, C. Argillier, \& A. Ceirans, 2011. Final results of intercalibration of Central-Baltic GIG macroinvertebrate methods for assessing ecological status of lakes. Intercalibration report, milestone 6. EU Commission, JRC. https://circabc.europa.eu/w/browse/c48010c0-863b-49e68f1a-22da029cd93b.

Brucet, S., S. Poikane, A. Lyche-Solheim \& S. Birk, 2013. Biological assessment methods for European lakes: ecological rationale and human impacts. Freshwater Biology 58.

Caroni, R. \& K. Irvine, 2010. The potential of zooplankton communities for ecological assessment of lakes: redundant concept or political oversight? Biology and Environment: Proceedings of the Royal Irish Academy 110B: 35-53.

Carvalho, L., C. A. Miller, E. M. Scott, G. A. Codd, P. S. Davies \& A. N. Tyler, 2011. Cyanobacterial blooms: statistical models describing risk factors for national-scale lake assessment and lake management. Science of the Total Environment 409: 5353-5358.

Carvalho, L., S.Poikane, A. L. Solheim, G. Phillips, G. Borics, J. Catalan, C. D. Hoyos, D. S., B. Dudley, M. Järvinen, C. Laplace-Treyture, K. Maileht, M. C., U. Mischke, J. Moe, G. Morabito, P. Nõges, T. Nõges, I. Ott, A. Pasztaleniec, B. Skjelbred \& S. J. Thackeray, 2012. Strength and 
uncertainty of lake phytoplankton metrics for assessing eutrophication impacts in lakes. Hydrobiologia, this issue. doi:10.1007/s10750-012-1344-1.

CEN, 2005. Water quality - sampling of fish with multi-mesh gillnets, EN 14757: 2005.

Clarke, R., 2012. Estimating confidence of European WFD ecological status class and WISER Bioassessment Uncertainty Guidance Software (WISERBUGS). Hydrobiologia, this issue. doi:10.1007/s10750-012-1245-3.

Dolman, A. M., J. Rücker, F. R. Pick, J. Fastner, T. Rohrlack, U. Mischke \& C. Wiedner, 2012. Cyanobacteria and cyanotoxins: the influence of nitrogen versus phosphorus. PLoS ONE 7(6): e38757.

Dudley, B., M. Dunbar, E. penning, A. Kolada, S. Hellsten, A. Oggioni, V. Bertrin \& M. Søndergaard, 2012. Measurements of uncertainty in macrophyte metrics used to assess European lake water quality. Hydrobiologia, this issue. doi: 10.1007/s10750-012-1338-z.

EC, 2000. Directive 2000/60/EC of the European Parliament and the Council of 23rd October 2000 establishing a framework for Community action in the field of water policy (OJ L 327, 22/12/2000 p. 1-72) (http://eur-lex.europa. eu/LexUriServ/LexUriServ.do?uri=OJ:L:2000:327:0001:0072: EN:PDF). Accessed 5 Oct 2012.

EEA-ETC, 2012. Ecological and chemical status and pressures in European waters. Thematic Assessment for EEA Water 2012 Report, 146 pp. http://icm.eionet.europa.eu/ETC_ Reports/EcoChemStatusPressInEurWaters_201211.

Emmrich, M., S. Brucet, I. J. Winfield, E. Jeppesen, T. L. Lauridsen, P. Volta, C. Argillier, S. Pedron, K. Holmgren, T. Hesthagen, D. Ritterbusch \& T. Mehner, 2011. Changes in size structure of fish assemblages in European lakes along eutrophication and hydromorphological pressure gradients. WISER Deliverable 3.4-2: 53 pp. http://www.wiser.eu/ results/deliverables/.

Emmrich, M., I. J. Winfield, J. Guillard, A. Rustadbakken, C. Vergès, P. Volta, E. Jeppesen, T. L. Lauridsen, K. Holmgren, C. Argillier \& T. Mehner, 2012a. Comparison of hydroacoustic and multi-mesh gillnet data. WISER Deliverable 3.4-5. http://www.wiser.eu/results/deliverables/.

Emmrich, M., I. Winfield, J. Guillard, A. Rustadbakken, C. Vergès, P. Volta, E. Jeppesen, T. Lauridsen, S. Brucet, K. Holmgren, C. Argillier, Christine \& T. Mehner, 2012b. Strong correspondence between gillnet catch per unit effort and hydroacoustically derived fish biomass in stratified lakes. Freshwater Biology. 57: 2436-2448.

Hellsten, S. 2001. Effects of lake water level regulation on aquatic macrophytes stands and options to predict these impacts under different conditions. Acta Botanica Fennica. 171, $47 \mathrm{p}$.

Hellsten, S., D. Tierney, M. Mjelde, F. Ecke, N. Willby \& G. Phillips, 2011. Final results of intercalibration of NGIG macrophyte methods for assessing ecological status of Northern European lakes. Intercalibration report, milestone 6. EU Commission, JRC. https://circabc.europa.eu/w/ browse/c48010c0-863b-49e6-8f1a-22da029cd93b.

Hering, D., A. Borja, L. Carvalho \& C. K. Feld, 2013. Assessment and recovery of European water bodies: key messages from the WISER project. Hydrobiologia, this issue. doi:10.1007/s10750-012-1438-9.
James, C., J. Fisher, V. Russell, S. Collings \& B. Moss, 2005. Nitrate availability and hydrophyte species richness in shallow lakes. Freshwater Biology 50: 1049-1063.

Jensen, J. P., E. Jeppesen, K. Olrik \& P. Kristensen, 1994. Impact of nutrients and physical factors on the shift from cyanobacterial to chlorophyte dominance in shallow Danish Lakes. Canadian Journal of Fisheries and Aquatic Sciences 51: 1692-1699.

Jeppesen, E., M. Søndergaard, M. Søndergaard \& K. Christoffersen, 1998. The structuring role of submerged macrophytes in lakes. Springer, New York.

Jeppesen, E., M. Meerhoff, K. Holmgren, I. González-Bergonzoni, F. Teixeira-de Mello, S. A. J. Declerck, L. De Meester, M. Søndergaard, T. L. Lauridsen, R. Bjerring, J. M. Conde-Porcuna, N. Mazzeo, C. Iglesias, M. Reizenstein, H. J. Malmquist, Z. Liu, D. Balayla \& X. Lazzaro, 2010. Impacts of climate warming on lake fish community structure and potential effects on ecosystem function. Hydrobiologia 646: 73-90.

Jeppesen E., Nõges P., Davidson T.A., Haberman J., Nõges T., Blank K., Lauridsen T.L., Søndergaard M., Sayer C., Laugaste R., Johansson L.S., Bjerring R. \& Amsinck S.L., 2011. Zooplankton as indicators in lakes - a plea for including zooplankton in the ecological quality assessment of lakes according to the European Water Framework Directive (WFD). Hydrobiologia 676:270-297.

Jeppesen, E., T. Mehner, I. J. Winfield, K. Kangur, J. Sarvala, D. Gerdeaux, M. Rask, H. J. Malmquist, K. Holmgren, P. Volta, S. Romo, R. Eckmann, A. Sandström, S. Blanco, A. Kangur, H. R. Stabo, M. Tarvainen, A.-M. Ventelä, M. Søndergaard, T. L. Lauridsen \& M. Meerhoff, 2012. Impacts of climate warming on the long-term dynamics of key fish species in 24 European lakes. Hydrobiologia 694: $1-39$.

Karr, J. R. \& E. W. Chu, 1999. Restoring life in running waters. Island Press, Washington: $206 \mathrm{pp}$.

Kolada, A., S. Hellsten, M. Søndergaard, M. Mjelde, B. Dudley, G. van Geest, B. Goldsmith, T. Davidson, H. Bennion, P. Nõges \& V. Bertrin, 2011. Report on the most suitable lake macrophyte based assessment methods for impacts of eutrophication and water level fluctuations. Available at: www.wiser.eu/results/deliverables/.

Lauridsen, T. L., F. Landkildehus, E. Jeppesen, T. B. Jorgensen \& M. Søndergaard, 2008. A comparison of methods for calculating Catch Per Unit Effort (CPUE) of gill net catches in lakes. Fisheries Research 93: 204-211.

Lyche-Solheim, A., S. Rekolainen, S. Moe, L. Carvalho, G. Phillips, R. Ptacnik, W. Penning, L. Toth, C. O'Toole, A.K. Schartau \& T. Hesthagen, 2008. Ecological threshold responses in European lakes and their applicability for the Water Framework Directive (WFD) implementation: synthesis of lakes results from the REBECCA project. Aquatic Ecology 42: 317-334.

Lyche-Solheim, A., Phillips, G., Free, G., Drakare, S., Järvinen, M., Skjelbred, B. \& Trodd, W., 2011. Final results of intercalibration of NGIG phytoplankton methods for assessing ecological status of Northern European lakes. Intercalibration report, milestone 6. EU Commission, JRC. https://circabc.europa.eu/w/browse/c48010c0-863b-49e68f1a-22da029cd93b. 
Mason, C. F., 1981. Biology of freshwater pollution. Longman Scientific \& Technical, Harlow: 250 pp.

MEA, 2005. Millenium Ecosystem Assessment, General Synthesis Report, Island press, Washington DC.

Miler, O., M. Pusch, F. Pilotto, A. Solimini, E. McGoff, L. Sandin \& R. Clarke, 2012. Assessment of ecological effects of hydromorphological lake shore alterations and water level fluctuations using benthic invertebrates. WISER Deliverable D 3.3-4. 44 pp. http://www.wiser. eu/results/deliverables/.

Mischke, U., L. Carvalho, C. McDonald, B. Skjelbred, A. Lyche Solheim, G. Phillips, C. de Hoyos, G. Borics, J. Moe \& J. Pahissa, 2011. Phytoplankton bloom metrics. WISER deliverable 3.1-2. 48 pp. http://www.wiser.eu/results/ deliverables/.

Mjelde, M., S. Hellsten \& F. Ecke, 2012. A water level drawdown index for aquatic macrophytes in Nordic lakes. Hydrobiologia, this issue. doi:10.1007/s10750-012-1323-6.

Moe, J., A. Schmidt-Kloiber, B. Dudley \& D. Herring, 2012. The WISER way of organising ecological data from European rivers, lakes and transitional/coastal waters. Hydrobiologia this issue. doi:10.1007/s10750-012-1337-0.

Moss, B., 1990. Engineering and biological approaches to the restoration from eutrophication of shallow lakes in which aquatic plant communities are important components. Hydrobiologia 200/201: 367-377.

Moss, B., 2008. The Water Framework Directive: total environment or political compromise? Journal of the Total Environment 400: 32-41.

Phillips, G., O. P. Pietiläinen, L. Carvalho, A. Solimini, A. Lyche-Solheim \& A. Cardoso, 2008. Chlorophyll-nutrient relationships of different lake types using a large European dataset. Aquatic Ecology 42: 213-226.

Phillips, G., U. Mischke, J. Van Wichelen, M. Søndergaard, I. Karottki, I. Ott, K. Maileht, Laplace-Treyture, I. Olenina, M. Cicendajeva, W. Trodd, G. Free, R. Portielje \& A. Pasztaleniec, 2011. Final results of intercalibration of CBGIG phytoplankton methods for assessing ecological status of Central and Baltic European lakes. Intercalibration report, milestone 6. EU Commission, JRC. https:// circabc.europa.eu/w/browse/c48010c0-863b-49e6-8f1a22da029cd93b.

Phillips, G., A., Lyche-Solheim, B. Skjelbred, U. Mischke, S. Drakare, G. Free, M. Järvinen, C. de Hoyos, G. Morabito, S. Poikane \& L. Carvalho, 2012. A phytoplankton trophic index to assess the status of lakes for the Water Framework Directive. Hydrobiologia, this issue. doi:10.1007/s10750012-1390-8.

Pilotto, F., A. G. Solimini, M. Gevrey, C. Argillier, O. Miler, M. Pusch \& J. Böhmer, 2011. Development of tools for the assessment of European lakes using benthic invertebrates: A preliminary analysis. Project report WISER Deliverable D3.3-3. http://www.wiser.eu/results/deliverables/.

Poikane, S., 2009. Water Framework Directive intercalibration technical report. Part 2:Lakes. JRC Scientific and Technical Reports, European Commission, Luxembourg, EUR 23838 EN/2. doi:10.2788/23415, 176 pp.
R Development Core Team, 2009. R: A Language and Environment for Statistical Computing. R Foundation for Statistical Computing, Vienna.

Raun, A.-M. L., J. Borum \& K. S. Jensen, 2010. Influence of sediment organic enrichment and water alkalinity on growth of aquatic isoetid and elodeid plants. Freshwater Biology 55: 1891-1904.

Revelle, W. 2012. Package "psych", version 1.2.8. Procedures for Psychological, Psychometric, and Personality Research. http://personality-project.org/r/psych.manual.pdf. Also available as online calculation tool at http://www.vassarstats. net/rdiff.html.

Rowan, J. S., 2008. Lake Habitat Survey in the United Kingdom. Field survey guidance manual. Version 4. Dundee, The Scotland and Northern Ireland forum for environmental research (SNIFFER) \& Scottish Natural Heritage (SNH).

Rowan, J. S., J. Carwardine, R. W. Duck, O. M. Bragg, A. R. Black, M. E. J. Cutler, I. Soutar \& P. Boon, 2006. Development of a technique for Lake Habitat Survey (LHS) with applications for the European Union Water Framework Directive. Aquatic Conservation: Marine and Freshwater Ecosystems 16: 637-657.

Sandin, L. \& A. Solimini, 2012. (eds). Assessing human induced pressures on European lake ecosystems using benthic invertebrates: the importance of spatial variation. Fundamental and Applied Limnology, 180, no. 2, Archiv für Hydrobiologie.

Scheffer, M., S. H. Hosper, M. L. Meijer, B. Moss \& E. Jeppesen, 1993. Alternative equilibria in shallow lakes. Trends in Ecology and Evolution 8: 275-279.

Solimini, A., A. Cardoso, J. Carstensen, G. Free, A.-S. Heiskanen, N. Jepsen, P. Nòges, S. Poikane \& W. van de Bund, 2008. The monitoring of ecological status of European freshwaters. Wiley, Chippenham, Wiltshire.

Søndergaard, M., G. Phillips, S. Hellsten, A. Kolada, F. Ecke, H. Mäemets, M. Mjelde, M. M. Azzella \& A. Oggioni, 2012. Maximum growing depth of submerged macrophytes in European lakes. Hydrobiologia, this issue. doi:10.1007/ s10750-012-1389-1.

Thackeray, S. J., P. Nõges, M. J. Dunbar, B. J. Dudley, B. Skjelbred, G. Morabito, L. Carvalho, G. Phillips \& U. Mischke, 2011. Uncertainty in lake phytoplankton metrics. WISER deliverable D3.1.3: 42 pp. http://www.wiser. eu/results/deliverables/.

WFD-CIS, 2009. Common Implementation Strategy for the Water Framework Directive (2000/60/EC). Guidance Document on the Intercalibration Process 2008-2011. Guidance Document No 14: European Commission, Luxembourg. $102 \mathrm{pp}$.

WHO, 1999. Toxic Cyanobacteria in water: a guide to their public health consequences, monitoring and management. E \& F N Spon, London: 400 pp.

Zar, J. H., 1996. Biostatistical Analysis, 3rd ed. Prentice-Hall, London: $662 \mathrm{pp}$. 